\title{
Rrp15p, a novel component of pre-ribosomal particles required for 605 ribosome subunit maturation
}

\author{
MARIA LAURA DE MARCHIS, ${ }^{1}$ ALESSANDRA GIORGI, ${ }^{2}$ MARIA EUGENIA SCHININÀ, ${ }^{2}$ IRENE BOZZONI, ${ }^{1}$ and \\ ALESSANDRO FATICA ${ }^{1}$ \\ ${ }^{1}$ Dipartimento di Genetica e Biologia Molecolare, and ${ }^{2}$ Dipartimento di Scienze Biochimiche "A. Rossi Fanelli," Centro di Eccellenza di \\ Biologia e Medicina Molecolare (BEMM), Lab. di Genomica e Proteomica Funzionale degli Organismi Modello, Universita' di Roma "la \\ Sapienza," 00185, Rome, Italy
}

\begin{abstract}
In eukaryotes ribosome biogenesis required that rRNAs primary transcripts are assembled in pre-ribosomal particles and processed. Protein factors and pre-ribosomal complexes involved in this complex pathway are not completely depicted. The essential ORF YPR143W encodes in yeast for an uncharacterized protein product, named here Rrp15p. Cellular function of Rrp15p has not so far defined even if nucleolar location was referred. With the aim to define the possible role of this orphan gene, we performed TAP-tagging of Rrp15p and investigated its molecular association with known pre-ribosomal complexes. Comparative sucrose gradient sedimentation analyses of yeast lysates expressing the TAP-tagged Rrp15p, strongly indicated that this protein is a component of the pre-60S particles. Northern hybridization, primer extension and functional proteomics on TAP-affinity isolated complexes proved that Rrp15p predominately associated with pre-rRNAs and proteins previously characterized as components of early pre-60S ribosomal particles. Finally, depletion of Rrp15p inhibited the accumulation of $27 \mathrm{~S}$ and $7 \mathrm{~S}$ pre-rRNAs and $5.8 \mathrm{~S}$ and $25 \mathrm{~S}$ mature rRNA. These results provide the first indication that Rrp15p is a novel factor involved in the early maturation steps of the $60 \mathrm{~S}$ subunits. Moreover, the identification of the protein kinase CK2 in the Rrp15p-containing pre-ribosomal particles here reported, sustains the link between ribosome synthesis and cell cycle progression.
\end{abstract}

Keywords: pre-rRNA; ribosome synthesis; 60S

\section{INTRODUCTION}

Ribosome synthesis in eukaryotes starts in the nucleolus with the transcription of a large precursor RNA (pre-rRNA) by RNA polymerase I. This primary transcript is subsequently chemically modified by a myriad of small nucleolar ribonucleoprotein complexes (snoRNPs) and mature 18S, $5.8 \mathrm{~S}$, and 25-28S rRNAs are produced by a complex series of endo- and exo-nucleolytic cleavage steps (Fig. 1; for review, see Venema and Tollervey 1999). During these processing reactions, the rRNA intermediates associate with the $5 \mathrm{~S}$ rRNA, about 80 ribosomal proteins and a large number of nonribosomal proteins, to form pre-ribosomal particles. The pre-ribosomal particles are dynamically remodeled and matured as they transit from the nucleolus to the nucleo-

Reprint requests to: Alessandro Fatica, Dipartimento di Genetica e Biologia Molecolare, Universita' di Roma "la Sapienza," P.le Aldo Moro 5, 00185, Rome, Italy; e-mail: alessandro.fatica@uniroma1.it; fax: +39-0649912500.

Article and publication are at http://www.rnajournal.org/cgi/doi/ 10.1261/rna.7200205. plasm and then are exported to the cytoplasm, where synthesis of the $60 \mathrm{~S}$ and $40 \mathrm{~S}$ ribosomal subunits is completed (Tschochner and Hurt 2003).

An outline of ribosome assembly pathway was provided in yeast by tandem affinity purifications (TAP method) of tagged trans-acting factors required for pre-rRNA processing (Harnpicharnchai et al. 2001; Fatica et al. 2002; Gavin et al. 2002; Grandi et al. 2002; Nissan et al. 2002; Saveanu et al. 2003; Schafer et al. 2003). Such studies identified several pre-ribosomal particles containing more than 140 proteins transiently associated with pre-rRNAs (for review, see Fatica and Tollervey 2002; Fromont-Racine et al. 2003; Milkereit et al. 2003; Tschochner and Hurt 2003). Comparison of the RNA and proteins associated with these complexes led to a depiction of the succession of pre-ribosomal particles and showed a remarkable separation of the factors involved in the synthesis of the $40 \mathrm{~S}$ and $60 \mathrm{~S}$ ribosomal subunits.

In this study, we characterize an as yet unknown component of early pre-60S ribosomal particles, ypr143w (now Rrp15p), which is required for the maturation of large subunit rRNAs. 


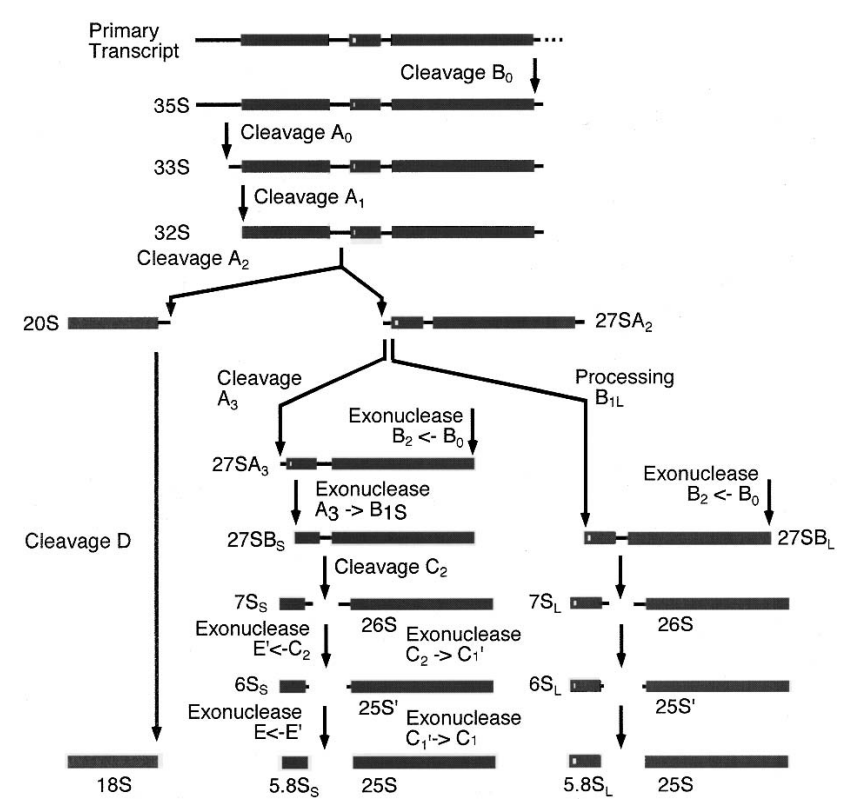

FIGURE 1. Pre-rRNA processing pathway. In wild-type cells, the $35 \mathrm{~S}$ pre-rRNA is cleaved at site $A_{0}$ producing the $33 S$ pre-rRNA. This molecule is rapidly cleaved at site $A_{1}$ to produce the $32 \mathrm{~S}$, which is cleaved at site $\mathrm{A}_{2}$ releasing the $20 \mathrm{~S}$ and $27 \mathrm{SA}_{2}$ pre-rRNAs. The $20 \mathrm{~S}$ pre-rRNA is exported to the cytoplasm where it is dimethylated by Dimlp and then cleaved at site $\mathrm{D}$, by an unidentified enzyme, to generate the mature $18 \mathrm{~S}$ rRNA. $27 \mathrm{SA}_{2}$ is processed via two alternative pathways. It is either cut at site $\mathrm{A}_{3}$ to generate $27 \mathrm{SA}_{3}$, which is then trimmed to site $\mathrm{B}_{1 \mathrm{~S}}$, producing $27 \mathrm{SB}_{\mathrm{S}}$. Alternatively, it can be processed to $27 \mathrm{SB}_{\mathrm{L}}$ by an as yet unknown mechanism. $27 \mathrm{SB}_{\mathrm{S}}$ and $27 \mathrm{SB}_{\mathrm{L}}$ are matured to the $5.8 \mathrm{~S}$ and $25 \mathrm{~S}$ following identical pathways. Cleavage at site $\mathrm{C}_{2}$ generates the $7 \mathrm{~S}$ and $26 \mathrm{~S}$ pre-rRNAs. The $7 \mathrm{~S}$ pre-rRNA is digested $3^{\prime}$ to $5^{\prime}$ to $6 \mathrm{~S}$ pre-rRNA and then to the mature $5.8 \mathrm{~S}$ rRNA. The $26 \mathrm{~S}$ pre-rRNA is digested $5^{\prime}$ to $3^{\prime}$ to the $25 \mathrm{~S}^{\prime}$ pre-rRNA and then to the mature $25 \mathrm{~S}$ rRNA. (For a review on pre-rRNA processing and the known processing enzymes see Venema and Tollervey 1999.)

\section{RESULTS}

\section{Rrp15p is an essential evolutionarily conserved protein that associates with pre-60S ribosomal particles}

The essential ORF YPR143w encoded for a protein of 28 $\mathrm{kDa}$. We termed this protein Rrp15p (Ribosomal RNA Processing). Sequence analyses identified putative orthologs in fungi and higher eukaryotes (Fig. 2), indicating that these proteins perform evolutionary conserved functions. However, there was no sequence similarity between Rrp15p and known protein domains.

GFP-tagged Rrp15p has been localized to the nucleus with consistent nucleolar enrichment (Huh et al. 2003) and, in a large-scale study, associated with different large subunit rRNA processing factors (Ho et al. 2002). Although Rrp15p has not been so far identified in the protein complexes described in the ribosome assembly pathway (Harnpicharnchai et al. 2001; Fatica et al. 2002; Gavin et al. 2002; Grandi et al. 2002; Nissan et al. 2002; Saveanu et al. 2003; Schafer et al. 2003), overall these data suggested its involvement in the ribosome biogenesis.

To assess the association of Rrp15p with pre-ribosomal particles, we performed a sucrose gradient analysis with a lysate from a C-terminal TAP tagged strain (Rrp15-TAP). This construct supported wild-type growth, showing it to be fully functional (Fig. 3). Furthermore, steady-state rRNA levels in the TAP-tagged strain are identical to the wild-type one (see Fig. 4B,C).

The sedimentation of Rrp15-TAP was determined by Western blotting and compared to that of the rRNA and pre-rRNA species (Fig. 4A). Comparison to the position of the mature rRNAs detected by ethidium staining (data not shown) indicated that Rrp15-TAP is enriched in the 60S of the gradient, with a weaker peak around $80 \mathrm{~S}$ to $90 \mathrm{~S}$ regions. Northern hybridization showed that the peak of Rrp15-TAP coincides with the peak of 27SA and 27SB pre-rRNAs. These analyses strongly indicate that Rrp15p is a component of the pre-60S particles.

To confirm these data, we identified the RNAs and proteins physically associated with Rrp15p using the TAP tag purification procedure. RNAs coprecipitated with Rrp15TAP were analyzed by Northern hybridization (Fig. 4B,C) and primer extension (Fig. 4D). An isogenic nontagged wild-type strain was utilized as control. Coprecipitation was seen for the $27 \mathrm{SA}_{2}, 27 \mathrm{SA}_{3}, 27 \mathrm{SB}$, and $7 \mathrm{~S}$ pre-rRNAs and mature $5 \mathrm{~S}$ rRNAs. The $7 \mathrm{~S}$ pre-rRNA was detected with much lower abundance than $27 \mathrm{~S}$ species (Fig. 4B,C). No precipitation was seen for $35 \mathrm{~S}$ and $6 \mathrm{~S}$ pre-rRNAs (data not shown) and for mature $18 \mathrm{~S}$ and $25 \mathrm{~S}$ rRNAs (Fig. 4C). Consistent with the sedimentation data, we conclude that Rrp15p predominately associated with the $27 \mathrm{~S}$ pre-RNAs of the large ribosome subunit.

To identify the proteins associated with Rrp15-TAP, we performed a SDS-PAGE of purified proteins followed by Coomassie staining (Fig. 4E). Bands were excised and analyzed by MALDI-Tof mass spectrometry. Rrp15-TAP copurified with a number of nonribosomal proteins, including Rlp7p, Rrp1p, Nop1p, Brx1p, Rpf1p, Rpf2p, Nop16p, Tif6p, Haslp, Nop56p, Nog1p, Puf6p, Nsalp, and Loclp, all of which were previously described as components and/or were implicated in 60S biogenesis (Fabian and Hopper 1987; Tollervey et al. 1991; Gautier et al. 1997; Venema and Tollervey 1999; Dunbar et al. 2000; Harnpicharnchai et al. 2001; Fatica et al. 2002; Wehner and Baserga 2002; Nissan et al. 2002; Kallstrom et al. 2003; Emery et al. 2004). In addition, only ribosomal proteins of the large subunit were identified (Rpl4p, Rpl5p, Rpl7p, Rpl8p, Rpl13p, Rpl15p, Rpl1p, Rpl16p, Rpl17p, and Rpl14p). We detected also the Ckalp subunit of the yeast protein kinase CK2. Components of this holoenzyme have been identified in other pre-ribosomal particles (Gavin et al. 2002; Ho et al. 2002) and this interaction may provide an additional link between ribosome synthesis and cell cycle progression (see Discussion). 


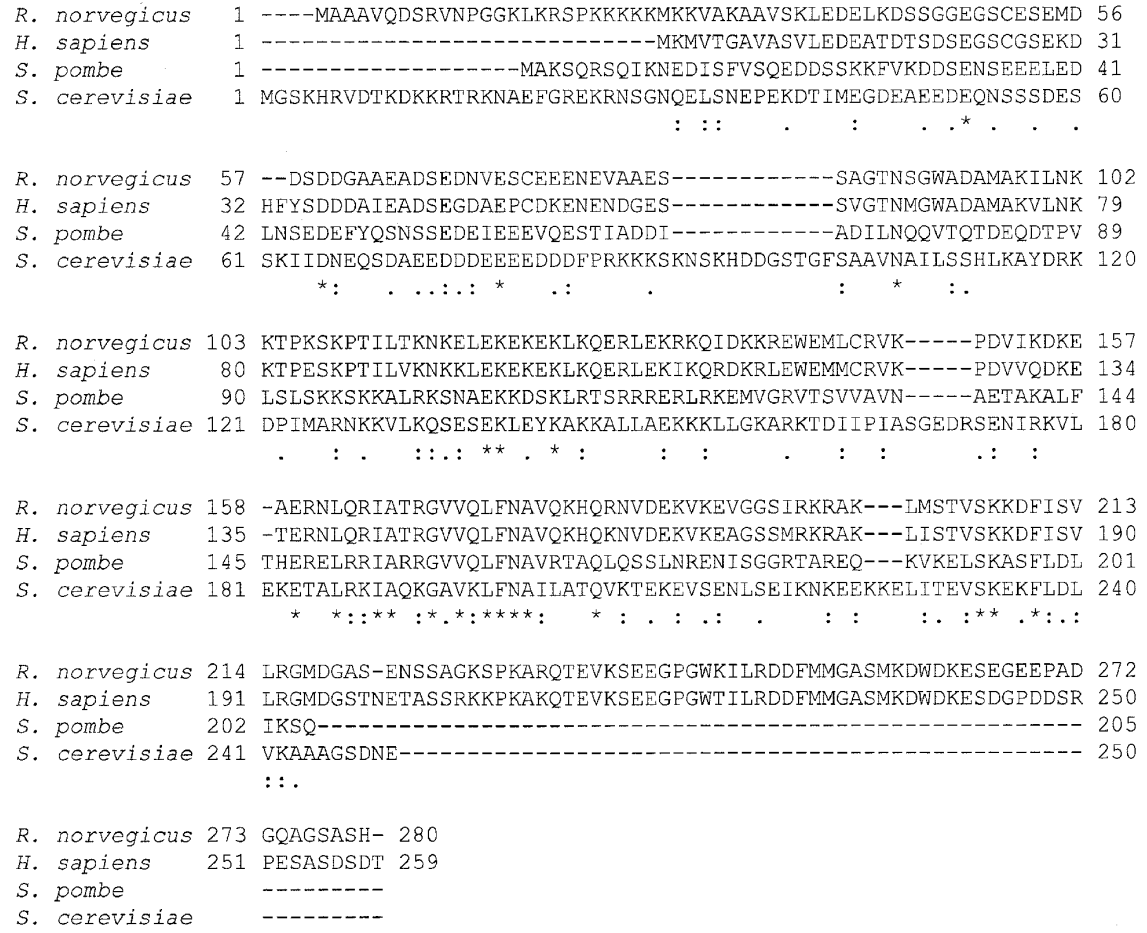

FIGURE 2. Multiple sequence alignment of Rrp15p and related proteins. The full sequences of Rrp15p and its putative eukaryotic orthologs were aligned using PSI-BLAST (Altschul et al. 1997). Putative orthologs in Rattus norvegicus (XP_341170.1), Homo sapiens (AAH20641.1), Schizosaccharomyces pombe (NP_592956), and Saccharomyces cerevisiae (YPR143W) are shown.

All together, these data demonstrate that Rrp15p is a new component of pre-60S particles, with a weaker and transient association with the earlier $90 \mathrm{~S}$ preribosomes.

\section{Rrp15p is required for the synthesis of large subunit rRNAs}

The association of Rrp15p with pre-60S particles suggested its involvement in subunit maturation. To investigate this, a chromosomal HA-tagged Rrp15p fusion protein was created under the control of the repressible GAL1 promoter, GAL::HA-rrp15 (Longtine et al. 1998). In galactose liquid media, growth of the GAL::HA-rrp15 and of an isogenic wildtype strain was very similar (data not shown). Following transfer to glucose liquid medium, the growth rate of both strains was initially the same but growth of the GAL::HA-rrp15 strain was strongly reduced after $8 \mathrm{~h}$ and almost ceased by $16 \mathrm{~h}$ (Fig. $5 \mathrm{~A})$. Western blot analysis using anti-HA antibodies revealed that the decrease in growth rate in glucose medium was concomitant with HA-Rrp15p depletion (Fig. 5B).

Pre-rRNA processing was subsequently assessed by Northern hybridizations, primer extension analyses (Fig. 6) and pulse-chase labeling (Fig. 7).

Steady-state levels of mature and precursor rRNA molecules were determined by Northern hybridization with oligonucleotides specific for the pre-rRNAs and mature rRNAs (Fig. 6). Analysis of high molecular weight rRNAs showed that Rrp15p depletion leads to reduce levels of $25 \mathrm{~S}$ and $18 \mathrm{~S}$ rRNAs. Consistent with its putative role in $60 \mathrm{~S}$ maturation, 25S production is significantly reduced relative to $18 \mathrm{~S}$ rRNA synthesis (Fig. 6B). As other pre-60S protein components, depletion of Rrp15p led to accumulation of the 35S pre-rRNA (Fig. 6B) and to reduction of the $27 \mathrm{SA}_{2}$ and $27 \mathrm{SB}$. The $20 \mathrm{~S}$ pre-rRNA was also reduced with concomitant appearance of the aberrant 23S RNA. This is consistent with the delay in early prerRNA processing steps at site $A_{0}, A_{1}$, and $A_{2}$ seen in many others processing mutants involved in large subunit maturation (Venema and Tollervey 1999). After the shift to glucose medium a rapid and strong reduction was seen in the level of 7S pre-rRNA (Fig. 6C), which is generated by cleavage at site $\mathrm{C}_{2}$ in the 27SB (see Fig. 1A). Together with the accumulation of the $\mathrm{A}_{2}-\mathrm{C}_{2}$ fragment (Fig. 6C), this indicates that in the absence of Rrp15p the $27 \mathrm{SA}_{2}$ is not processed at sites $\mathrm{A}_{3}$ and $\mathrm{B}_{1}$ but directly cleaved at site $\mathrm{C}_{2}$ (see Fig. 6E). Despite the drastic reduction in $7 \mathrm{~S}$ pre-rRNA level, primer extension analysis up to site $\mathrm{C}_{2}$ did not shown any reduction in the level of $26 \mathrm{~S}$ pre-rRNA, which is the other product of the $\mathrm{C}_{2}$ cleavage (Fig. $6 \mathrm{C}$ ). It is very likely that the $\mathrm{A}_{2}-\mathrm{C}_{2}$ fragment replaces the $7 \mathrm{~S}$ pre-rRNA in the normal base-pairing with the $26 \mathrm{~S}$, preventing their processing to mature rRNAs and leading both molecules to degradation (see Fig. 6E). This phenotype has been already

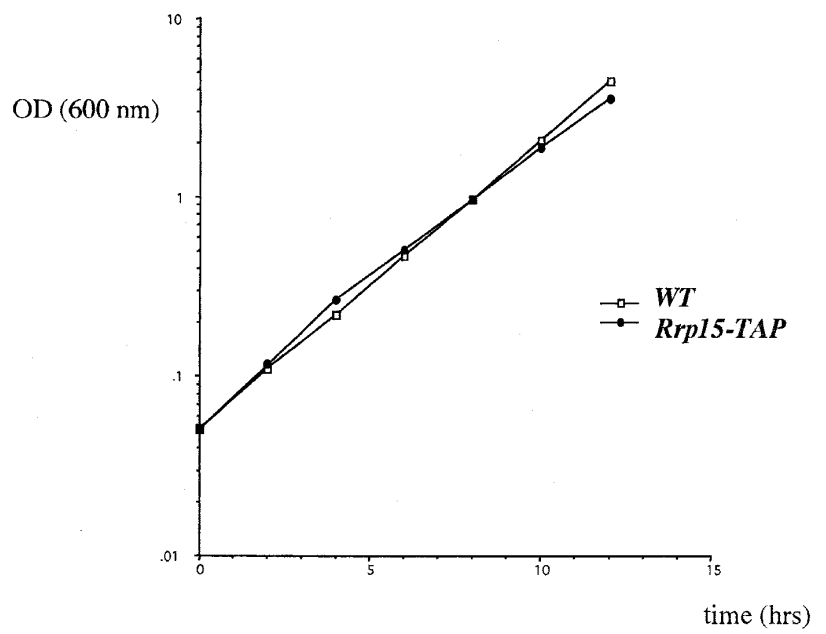

FIGURE 3. Tap-tagged Rrp15p supports wild-type growth. Growth rate of Rrp15-TAP (circles) and wild-type (squares) strains at $30^{\circ} \mathrm{C}$ in YPD. 

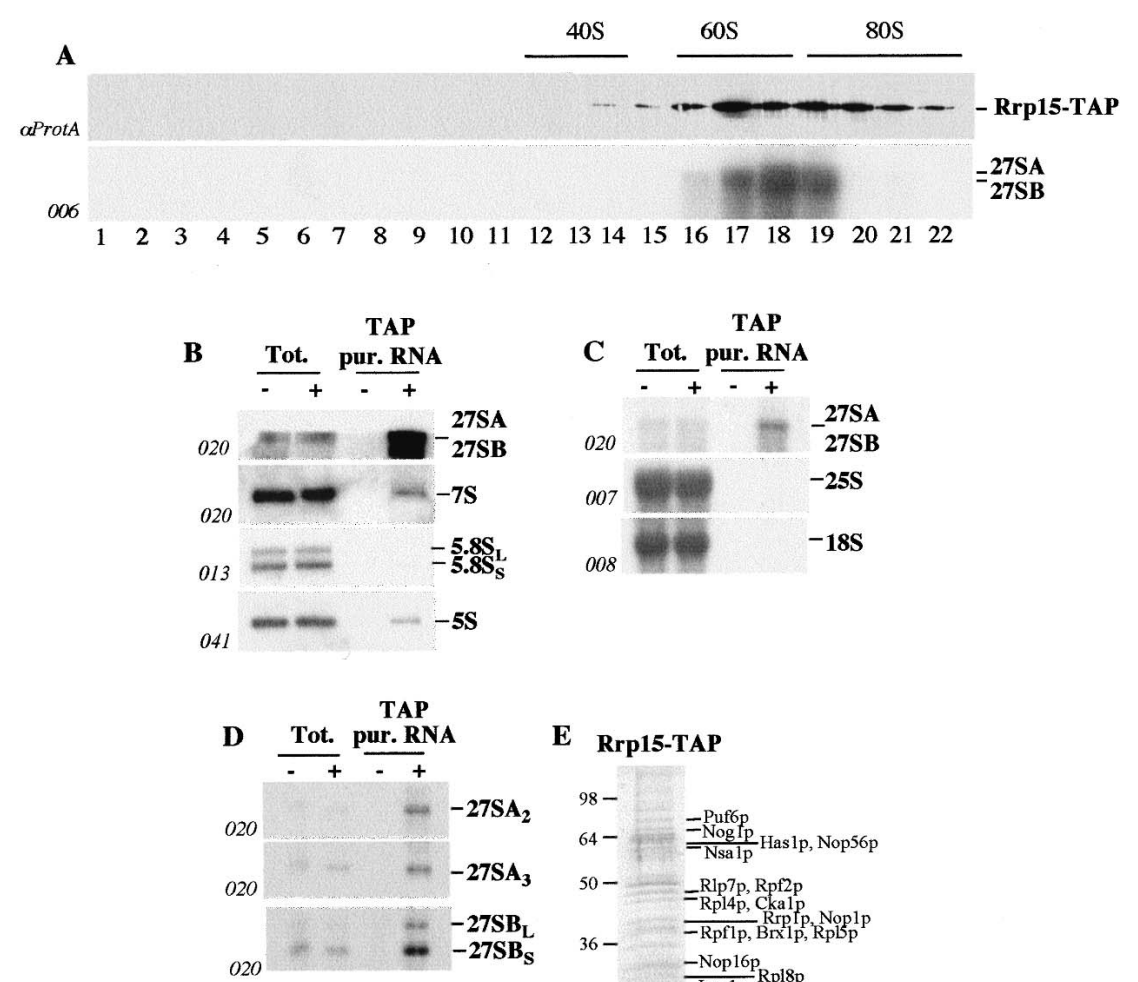

E Rrp15-TAP

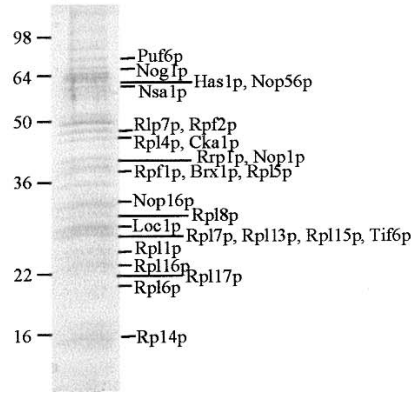

FIGURE 4. Rrp15p is associated with pre-60S ribosomal particles.(A) Upper panel: sedimentation of TAP tagged Rrp15p on a 10-50\% sucrose gradient. The levels of the Rrp15-TAP protein were determined by immunoblot analysis. Lower panel: The levels of the $27 \mathrm{~S}$ pre-rRNA were determined by Northern analysis. Positions of $40 \mathrm{~S}$ and $60 \mathrm{~S}$ ribosomal subunits and $80 \mathrm{~S}$ ribosomes are indicated, as determined by ethidium staining of the RNA recovered from each fraction (data not shown). (B,C) Northern analysis of low and high molecular weight rRNAs, respectively, and $(D)$ primer extension analyses of rRNAs and pre-rRNAs coprecipitated with Rrp15-TAP. RNA was extracted from whole cells (Tot. lane) and affinity purified fractions from tagged (+ lane) and the non-tagged isogenic wild-type strain (- lane). The Northern membrane was consecutively hybridized with the probes indicated (see Materials and Methods and Fig. 6A for locations of the probes used). (E) Purified proteins obtained from the TAP method were resolved by SDS-PAGE. Bands were visualized by Coomassie staining. The labeled bands were excised and identified by mass spectrometry. MALDI-ToF identified proteins are indicated.

described for other components of early pre-60S particles (Fatica et al. 2002, 2003; Dez et al. 2004; Rosado and de La Cruz 2004). Decrease levels of $5.8 \mathrm{~S}$ and $5 \mathrm{~S}$ mature rRNAs were also observed (Fig. 6C). The $5.8 \mathrm{~S}$ reduction is a consequence of the inhibition of the synthesis of its direct precursor $7 \mathrm{~S}$ pre-rRNA; while the diminution in $5 \mathrm{~S}$ rRNA accumulation is probably due to the reduction of large ribosomal subunits in which $5 \mathrm{~S}$ molecule has to be incorporated.

Pulse-chase analysis of the GAL::HA-rrp15 strain with $\left[{ }^{3} \mathrm{H}\right]$-uracil was performed $8 \mathrm{~h}$ after transfer to glucose medium (Fig. 7). Comparison of the wild type and mutant strains showed that overall incorporation of $\left[{ }^{3} \mathrm{H}\right]$-uracil was reduced upon Rrp15p depletion. However, the accumulation of 5.8S rRNA was delayed in the mutant strain.
From these results, we concluded that Rrp15p is required for large subunit rRNA maturation and, in particular, for proper processing of $27 \mathrm{SA}_{2}$ that leads to the production of $5.8 \mathrm{~S}$ and $25 \mathrm{~S}$ rRNAs.

\section{DISCUSSION}

Here we report the characterization of a new essential yeast gene, named $R R P 15$, required for the formation of $60 \mathrm{~S}$ ribosomal subunits. Sedimentation data and analysis of proteins and RNAs associated with Rrp15p indicate that it is a component of early pre-60S particles. In particular, the results presented in this study show that Rrp15p associates with pre-ribosomes at the step that separates the precursors to the $40 \mathrm{~S}$ and $60 \mathrm{~S}$ subunits. Coprecipitation of the $27 \mathrm{SA}_{2}$, $27 \mathrm{SA}_{3}$, and $27 \mathrm{SB}$, with lower efficiency of $7 \mathrm{~S}$ pre-rRNAs, but not of the mature $5.8 \mathrm{~S}$ and $25 \mathrm{~S}$ rRNAs indicate that Rrp15p remains associated in pre-ribosomal particles during all the processing steps of the $27 \mathrm{SA}_{2}$, dissociating at $\mathrm{C}_{2}$ cleavage. Indeed, as reported for other pre-60S components (Fatica et al. 2002, 2003; Dez et al. 2004; Rosado and de La Cruz 2004), the presence of Rrp15p is required to block premature cleavage of $27 \mathrm{SA}_{2}$ at site $\mathrm{C}_{2}$. This leads to the conclusion that the still unidentified endonuclease responsible for this cleavage event can act even on a not properly assembled preribosome and that the function of some pre-60S components is to provide quality control systems that guarantee the right timing of the $27 \mathrm{SA}_{2}$ processing events.

Surprisingly, Rrp15p has never been detected in any of the several ribosomal TAP complexes purified in these years (Harnpicharnchai et al. 2001; Fatica et al. 2002; Gavin et al. 2002; Grandi et al. 2002; Nissan et al. 2002; Saveanu et al. 2003; Schafer et al. 2003). However, it has been copurified with overexpressed tagged Nop7p together with other known pre-60S protein components in a large-scale purification study (Ho et al. 2002). This may be explained by the fact that pre-60S ribosomal particles are very dynamic and affinity purification results in different laboratories depend upon the purification protocol utilized and the growth phase of the tagged strains. Moreover, and this might be our case, some proteins might escape detection by mass-spectrometry. For these reasons, it is also very difficult to define the precise maturation stage of the pre-ribosomal particles containing 


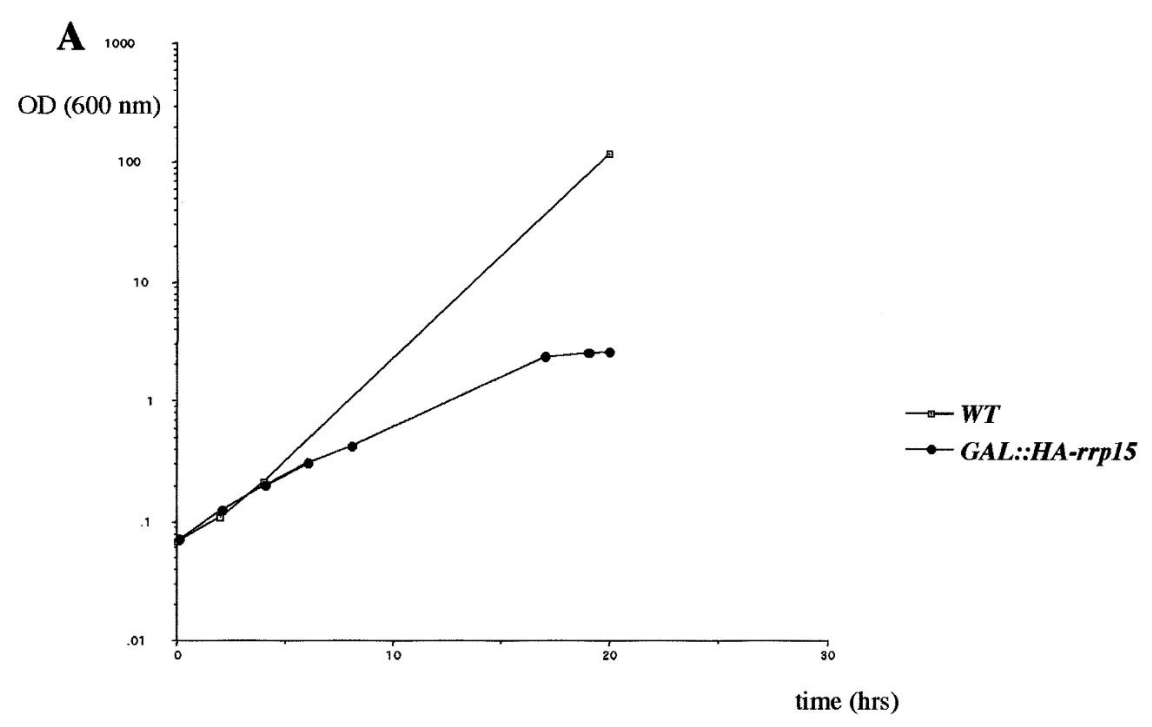

B

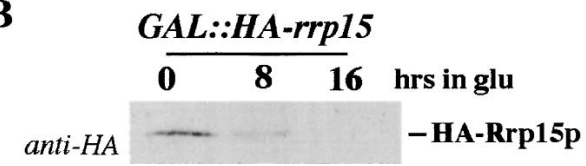

FIGURE 5. Depletion of Rrp15p inhibits growth. (A) Growth rates of the GAL::HA-rrp15 (circles) and wild-type (squares) strains following a shift from galactose to glucose medium. $(B)$ Western blot analysis of Rrp15p depletion. Whole cell extracts were prepared from samples harvested at the indicated times. Equal amount of proteins were separated by $10 \%$ SDS-PAGE and the HA-tag on HA-rrp15p was detected by Western blotting.

Rrp15p. Furthermore, it remains to be analyzed whether Rrp15p is required for the nuclear and/or nucleolar export of pre-60S particles.

Interestingly, in our purification we identified also the Cka1p subunit of the yeast casein kinase 2 (CK2). CK2 is a pleiotropic protein kinase that has crucial roles in cell differentiation, proliferation, and survival (for review, see Ahmed et al. 2002). It is able to phosphorylate over 300 proteins; between them are proteins affecting protein synthesis and ribosomal proteins of the large subunit (Zambrano et al. 1997; Meggio and Pinna 2003). This almost universal kinase CK2 has a quaternary structure composed of two catalytic (CKA1 and CKA2) and two regulatory subunits (CKB1 and CKB2). Interestingly, each CK2 subunit enters the nucleus as distinct subunits rather than as preassembled holoenzyme and they are integrated into different multimolecular complexes (Filhol et al. 2004). Components of this kinase have been already identified in several complexes containing pre-ribosomal proteins but their role in ribosome assembly is still unclear (Gavin et al. 2002; Ho et al. 2002). Several proteins involved in ribosome biogenesis have additional roles in cell cycle (Du and Stillman 2002; Zhang et al. 2002; Oeffinger and Tollervey 2003) and this association may provide a further link between these two processes. Further work is needed to clarify a possible role for Rrp15p in cell cycle progression.

\section{MATERIALS AND METHODS}

\section{Strains and microbiological techniques}

Standard techniques were employed for growth and handling of yeast. Yeast strains used in this work are: BMA38 (a, his $3 \Delta 200$, leu2-3,112, ura3-1, $\operatorname{trp} 1 \Delta$, ade2-1), YAF63 (a, his3 $\Delta 200$, leu2-3,112, ura3-1, $\operatorname{trp} 1 \Delta$, ade2-1, RRP15-TAP::TRP1), YMD1 (a, his3 $\Delta 200$, leu2-3,112, ura3-1, trp1 $\Delta$, ade2-1, KAN ::GAL::HA-RRP15). Strain YMD1 was created from BMA38 by use of a one-step PCR strategy as previously described (Longtine et al. 1998). TAP tagging of Rrp15p was performed as described in Rigaut et al. (1999).

\section{Sucrose gradient analysis and affinity purification}

Sucrose gradient centrifugation was performed as described (Tollervey et al. 1993; Baßler et al. 2001). RNA was extracted from each fraction and resolved on standard 1.2\% agarose/formaldehyde gel. Mature rRNAs and pre-rRNA species were detected by ethidium staining and Northern hybridization, respectively. Sedimentation of proteins was assayed by SDS-PAGE and TAP-tagged Rrp15p was detected by Western immunoblotting with peroxidase-conjugated rabbit IgG (Sigma). Affinity purification of TAP-tagged Rrp15p and analysis of copurified RNAs and proteins was performed as previously described (Fatica et al. 2002).

\section{Pulse-chase labeling}

Metabolic labeling of RNA was performed as described previously (Fatica et al. 2002). The strains GAL::HA-rrp15 and BMA38 were transformed with a plasmid containing the URA3 gene, pre-grown in galactose medium lacking uracil and transferred to glucose minimal medium for $8 \mathrm{~h}$. Cells at $0.3 \mathrm{OD}_{600 \mathrm{~nm}}$ were labeled with $\left[5,6-{ }^{3} \mathrm{H}\right]$ uracil for $1 \mathrm{~min}$ followed by a chase with excess unlabeled uracil for $1,2.5,5,10$, and $20 \mathrm{~min}$. Standard $6 \%$ polyacrylamide/urea gels was used to analyze the high molecular weight RNA species.

\section{RNA extraction, Northern hybridization, and primer extension}

For depletion of the Rrp15p protein, cells were harvested at intervals following a shift from RSG medium (2\% galactose, $2 \%$ 
$\mathbf{A}$

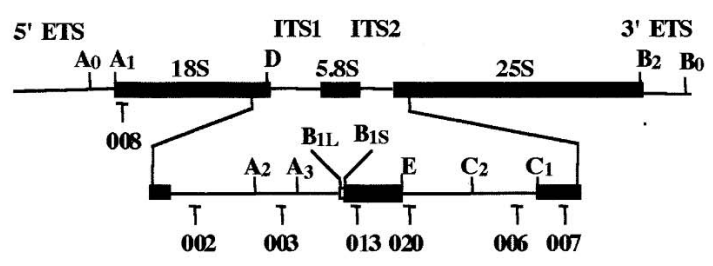

$\mathbf{B}$
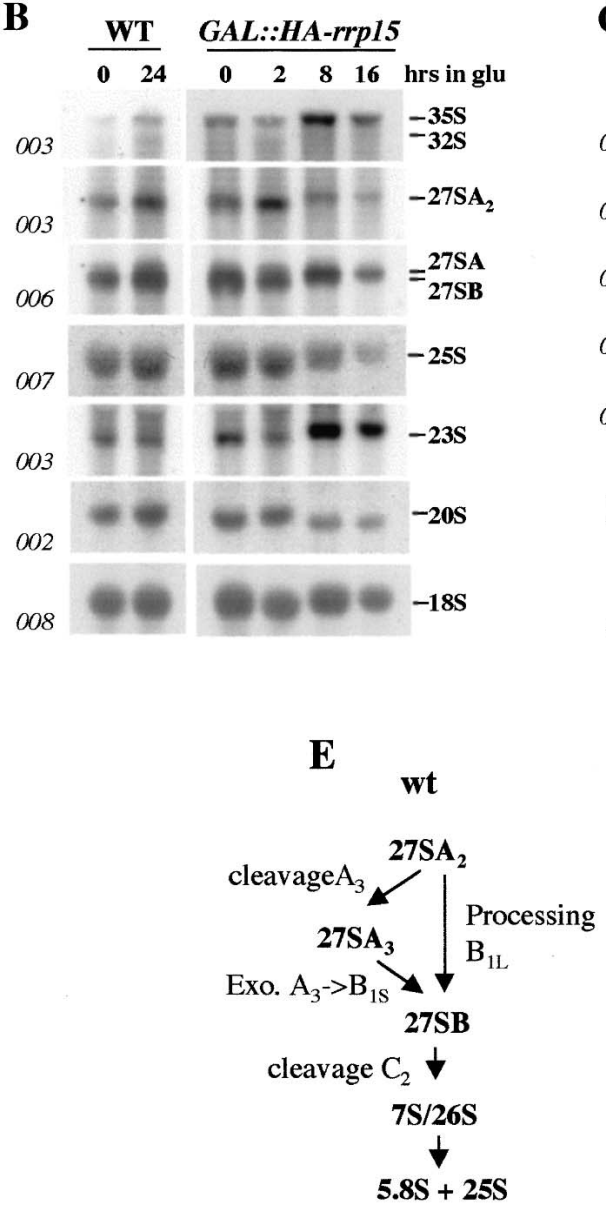

$1.2 \%$ agarose/formaldehyde and $6 \%$ acrylamide/urea gels were used to analyze the high and low molecular weight RNA species, respectively.

\section{Oligonucleotides}

For RNA hybridizations and primer extension analysis, the following oligonucleotides were used:
002, 5'-GCTCTTTGCTCTTGCC;
003, 5'-TGTTACCTCTGGGCCC;
006, 5'-GGCCAGCAATTTCAAGTTA;
007, 5' -CTCCGCTTATTGATATGC;
008, 5' -CATGGCTTAATCTTTGAGAC;
013, 5'-GCGTTGTTCATCGATGC;
020, 5' -TGAGAAGGAAATGACGCT; and
041 (anti-5S), 5'-CTACTCGGTCAGGCTC.

\section{Mass spectrometric analysis}

Selected protein bands were manually excised from gels and were simultaneously digested with trypsin using the In-gel Digest96 Kit (Millipore), according to the manufacturers instructions. Following enzymatic fragmentation, a minimal aliquot of the volume collected from each gel spot was mixed with an equal volume of a solution of $\alpha$-cyano-4-hydroxy-trans-cinnamic acid matrix saturated in $50 \%$ acetonitrile containing $0.1 \%$ trifluoroacetic acid. The obtained mixture was spotted onto a MALDI target plate and allowed to air-dry at room temperature. MALDI-ToF analyses were performed in a Voyager-DE STR instrument (Applied Biosystems) equipped with a $337 \mathrm{~nm}$ nitrogen laser and operating in reflector mode. Mass data were obtained by accumulating several spectra from laser shots with an accelerating voltage of $20,000 \mathrm{~V}$. All mass spectra were externally calibrated using a standard peptide mixture containing des-Arg-Bradykinin $(\mathrm{m} / z$ 904.4681), angiotensin I $(\mathrm{m} / \mathrm{z}$ 1296.6853), $1-17(\mathrm{~m} / \mathrm{z} 2093.0867)$ and $18-39$ $(\mathrm{m} / \mathrm{z} 2465.1989)$ adrenocorticotropic hormone fragments. Two tryptic autolytic peptides were also used for the internal calibration $(\mathrm{m} / \mathrm{z} 842.5100$ and 2807.3145).

\section{Database searches}

A monoisotopic mass list from each protein spot was obtained from MALDI-ToF sucrose, 2\% raffinose), or YPGal medium containing 2\% galactose, to YPD medium containing $2 \%$ glucose. Otherwise strains were grown in YPD medium. RNA was extracted as described previously (Kufel et al. 2000). Northern hybridizations and primer extension analysis were as described (Kufel et al. 2000). Standard

data after exclusion of contaminant mass values, corresponding to those expected from porcine trypsin and human keratins, automatically achieved by the PeakErazor program (http://www. protein.sdu.dk/gpmaw/Help/PeakErazor/peakerazor.html). These peptide mass fingerprints (PMF) were used to search for protein 


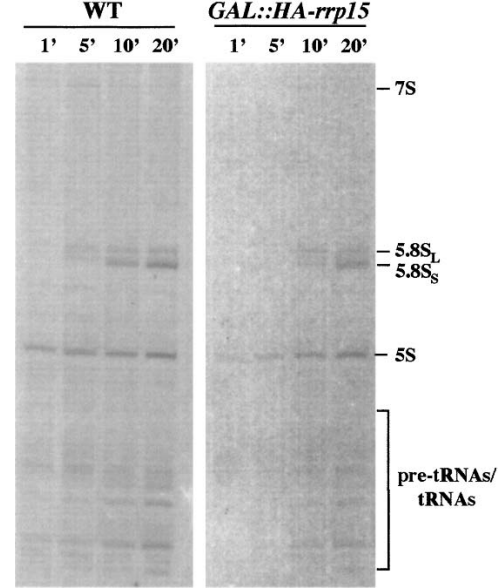

FIGURE 7. Depletion of Rrp15p inhibits pre-rRNA processing. $G A L:: H A-R r p 15$ and the isogenic wild-type strain were grown at $30^{\circ} \mathrm{C}$ in SDGal-Ura medium and then transferred to SDGlu-Ura for $8 \mathrm{~h}$. Cell were pulse labeled with $\left[5,6-{ }^{3} \mathrm{H}\right]$ uracil for $1 \mathrm{~min}$ and then chased with an excess of cold uracil. Total RNA was extracted from cell samples harvested at the indicated time points and resolved on $6 \%$ acrylamide/urea gels. The position of mature rRNAs, pre-rRNAs, and tRNA species are indicated.

candidates at the SwissProt database using the Mascot software program (www.matrixscience.com) according to these parameters: Saccharomyces cerevisiae as selected organism, one missed cleavage permission, and $50 \mathrm{ppm}$ measurement tolerance. Oxidation at methionine (variable modification) was also considered and positive identifications were accepted when at least five matching peptide masses were identified. No post-translational modifications were allowed.

\section{ACKNOWLEDGMENTS}

We thank M.S. Longtine for plasmids and M. Arceci for technical assistance. This work was supported by MURST (FIRB - p.n. RBNE015MPB and RBNE01KXC9-, PRIN-Cofin and "Centro di Eccellenza BEMM").

Received October 11, 2004; accepted December 21, 2004.

\section{REFERENCES}

Ahmed, K., Gerber, D.A., and Cochet, C. 2002. Joining the cell survival squad: An emerging role for protein kinase CK2. Trends Cell Biol. 12: $226-230$.

Altschul, S.F., Madden, T.L., Schaffer, A.A., Zhang, J., Zhang, Z., Miller, W., and Lipman, D.J. 1997. Gapped BLAST and PSIBLAST: A new generation of protein database search programs. Nucleic Acids Res. 25: 3389-3402.

Baßler, J., Granti, P., Gadal, O., Leßmann, T., Petfalski, E., Tollervey, D., and Lechner, J. 2001. Identification of a pre-ribosomal particle that is closely linked to nuclear export. Mol. Cell 8: 517-529.

Dez, C., Froment, C., Noaillac-Depeyre, J., Monsarrat, B., CaizerguesFerrer, M., and Henry, Y. 2004. Npalp, a component of very early pre-60S ribosomal particles, associates with a subset of small nucleolar RNPs required for peptidyl transferase center modification. Mol. Cell. Biol. 24: 6324-6337.

Du, Y.C. and Stillman, B. 2002. Yphlp, an ORC-interacting protein:
Potential links between cell proliferation control, DNA replication, and ribosome biogenesis. Cell 109: 835-848.

Dunbar, D.A., Dragon, F., Lee, S.J., and Baserga, S.J. 2000. A nucleolar protein related to ribosomal protein $\mathrm{L} 7$ is required for an early step in large ribosomal subunit biogenesis. Proc. Natl. Acad. Sci. 97: 13027-13032.

Emery, B., de la Cruz, J., Rocak, S., Deloche, O., and Linder, P. 2004. Haslp, a member of the DEAD-box family, is required for $40 \mathrm{~S}$ ribosomal subunit biogenesis in Saccharomyces cerevisiae. Mol. Microbiol. 52: 141-158.

Fabian, G.R. and Hopper, A.K. 1987. RRP1, a Saccharomyces cerevisiae gene affecting rRNA processing and production of mature ribosomal subunits. J. Bacteriol. 169: 1571-1578.

Fatica, A. and Tollervey, D. 2002. Making ribosome. Curr. Opin. Cell Biol. 14: 313-318.

Fatica, A., Cronshaw, A.D., Dlakic, M., and Tollervey, D. 2002. Ssf1p prevents premature processing of an early pre-60S ribosomal particle. Mol. Cell 9: 341-351.

Fatica, A., Oeffinger, M., Tollervey, D., and Bozzoni, I. 2003. Ciclp/ Nsa3p is required for synthesis and nuclear export of 605 ribosomal subunits. RNA 9: 1431-1436.

Filhol, O., Martiel, J.L., and Cochet, C. 2004. Protein kinase CK2: A new view of an old molecular complex. EMBO Rep. 5: 351-355.

Fromont-Racine, M.B., Senger, C., Saveanu, C., and Fasiolo, F. 2003. Ribosome assembly in eukaryotes. Gene 313: 17-42.

Gautier, T., Berges, T., Tollervey, D., and Hurt, E. 1997. Nucleolar KKE/D repeat proteins Nop56p and Nop58p interact with Nop1p and are required for ribosome biogenesis. Mol. Cell. Biol. 17: 70887098.

Gavin, A.C., Bosche, M., Krause, R., Grandi, P., Marzioch, M., Bauer, A., Schultz, J., Rick, J.M., Michon, A.M., and Cruciat, C.M., et al. 2002. Functional organization of the yeast proteome by systematic analysis of protein complexes. Nature 415: 141-147.

Grandi, P., Rybin, V., Bassler, J., Petfalski, E., Strauss, D., Marzioch, M., Schafer, T., Kuster, B., Tschochner, H., Tollervey, D., et al. 2002. 90S pre-ribosomes include the $35 \mathrm{~S}$ pre-rRNA, the U3 snoRNP, and $40 \mathrm{~S}$ subunit processing factors but predominantly lack 60S synthesis factors. Mol. Cell 10: 105-115.

Harnpicharnchai, P., Jakovljevic, J., Horsey, E., Miles, T., Roman, J., Rout, M., Meagher, D., Imai, B., Guo, Y., Brame, C.J., et al. 2001. Composition and functional characterization of yeast $66 \mathrm{~s}$ ribosome assembly intermediates. Mol. Cell 8: 663-670.

Ho, Y., Gruhler, A., Heilbut, A., Bader, G.D., Moore, L., Adams, S.L., Millar, A., Taylor, P., Bennett, K., Boutilier, K., et al. 2002. Systematic identification of protein complexes in Saccharomyces cerevisiae by mass spectrometry. Nature 415: 180-183.

Huh, W.K., Falvo, J.V., Gerke, L.C., Carroll, A.S., Howson, R.W., Weissman, J.S., and O'Shea, E.K. 2003. Global analysis of protein localization in budding yeast. Nature 425: 686-691.

Kallstrom, G., Hedges, J., and Johnson, A. 2003. The putative GTPases Nog1p and Lsg1p are required for 60S ribosomal subunit biogenesis and are localized to the nucleus and cytoplasm, respectively. Mol. Cell. Biol. 23: 4344-4355.

Kufel, J., Allmang, C., Chanfreau, G., Petfalski, E., Lafontaine, D.L.J., and Tollervey, D. 2000. Precursors to the U3 snoRNA lack snoRNP proteins but are stabilized by La binding. Mol. Cell. Biol. 20: 54155424.

Longtine, M.S., McKenzie, A.R., Demarini, D.J., Shah, N.G., Wach, A., Brachat, A., Philippsen, P., and Pringle, J.R. 1998. Aditional modules for versatile and economical PCR-based gene deletion and modification in Saccharomyces cerevisiae. Yeast 14: 953-961.

Meggio, F. and Pinna, L.A. 2003. One-thousand-and-one substrates of protein kinase CK2? FASEB J. 17: 349-368.

Milkereit, P., Kuhn, H., Gas, N., and Tschochner, H. 2003. The preribosomal network. Nucleic Acids Res. 31: 799-804.

Nissan, T.A., Bassler, J., Petfalski, E., Tollervey, D., and Hurt, E. 2002. $60 \mathrm{~S}$ pre-ribosome formation viewed from assembly in the nucleolus until export to the cytoplasm. EMBO J. 21: 5539-5547.

Oeffinger, M. and Tollervey, D. 2003. Yeast Nop15p is an RNA-bind- 


\section{De Marchis et al.}

ing protein required for pre-rRNA processing and cytokinesis. EMBO J. 22: 6573-6583.

Rigaut, G., Shevchenko, A., Rutz, B., Wilm, M., Mann, M., and Seraphin, B. 1999. A generic protein purification method for protein complex characterization and proteome exploration. Nat. Biotechnol. 17: 1030-1032.

Rosado, I.V. and de La Cruz, J. 2004. Npalp is an essential trans-acting factor required for an early step in the assembly of $60 \mathrm{~S}$ ribosomal subunits in Saccharomyces cerevisiae. RNA 10: 1073-1083.

Saveanu, C., Namane, A., Gleizes, P.E., Lebreton, A., Rousselle, J.C., Noaillac-Depeyre, J., Gas, N., Jacquier, A., and Fromont-Racine, M. 2003. Sequential protein association with Nascent 60S ribosomal particles. Mol. Cell. Biol. 23: 4449-4460.

Schafer, T., Strauss, D., Petfalski, E., Tollervey, D., and Hurt, E. 2003. The path from nucleolar $90 \mathrm{~S}$ to cytoplasmic $40 \mathrm{~S}$ pre-ribosomes. EMBO J. 22: 1370-1380.

Tollervey, D., Lehtonen, H., Carmo-Fonseca, M., and Hurt, E.C. 1991. The small nucleolar RNP protein NOP1 (fibrillarin) is required for pre-rRNA processing in yeast. $E M B O J .10: 573-583$.
Tollervey, D., Lehtonen, H., Jansen, R., Kern, H., and Hurt, E.C. 1993. Temperature-sensitive mutations demonstrate roles for yeast fibrillarin in pre-rRNA processing, pre-rRNA methylation, and ribosome assembly. Cell 72: 443-457.

Tschochner, H. and Hurt, E. 2003. Pre-ribosomes on the road from the nucleolus to the cytoplasm. Trends Cell Biol. 13: 255-263.

Venema, J. and Tollervey, D. 1999. Ribosome synthesis In Saccharomyces cerevisiae. Annu. Rev. Genet. 33: 261-311.

Wehner, K.A. and Baserga, S.J. 2002. The sigma(70)-like motif: A eukaryotic RNA binding domain unique to a superfamily of proteins required for ribosome biogenesis. Mol. Cell 9: 329339.

Zambrano, R., Briones, E., Remacha, M., and Ballesta, J.P.G. 1997. Phosphorylation of the acidic ribosomal $\mathrm{P}$ proteins in Saccharomyces cerevisiae: A reappraisal. Biochemistry 36: 1443614439.

Zhang, Y., Yu, Z., Fu, X., and Liang, C. 2002. Noc3p, a bHLH protein, plays an integral role in the initiation of DNA replication in budding yeast. Cell 109: 849-860. 

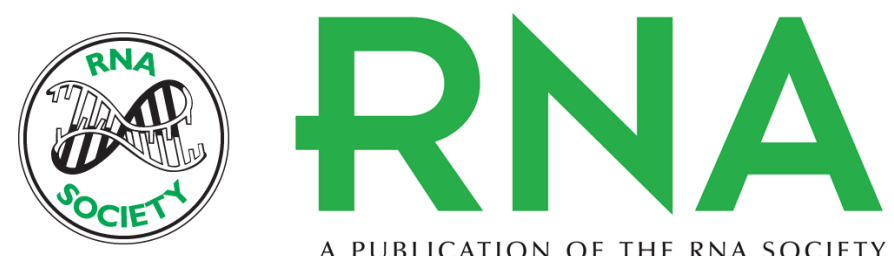

A PUBLICATION OF THE RNA SOCIETY

\section{Rrp15p, a novel component of pre-ribosomal particles required for 605 ribosome subunit maturation}

MARIA LAURA DE MARCHIS, ALESSANDRA GIORGI, MARIA EUGENIA SCHININÀ, et al.

RNA 2005 11: 495-502

References This article cites 37 articles, 13 of which can be accessed free at:

http://rnajournal.cshlp.org/content/11/4/495.full.html\#ref-list-1

\section{License}

Email Alerting Receive free email alerts when new articles cite this article - sign up in the box at the Service top right corner of the article or click here. 